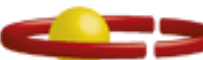 \\ Unce = \\ Centro Universitárıo de Brasílıa \\ CENTRO UNIVERSITÁRIO DE BRASÍLIA - UnICEUB \\ PROGRAMA DE INICIAÇÃO CIENTÍFICA
}

LUIZA RESENDE LARA GABRIEL

MAITÊ LÔBO KOLARIK

DETECÇÃO DE LEGIONELLA SPP. EM FONTES DE ÁGUA DA COMUNIDADE EM BRASÍLIA, DISTRITO FEDERAL.

BRASÍLIA 


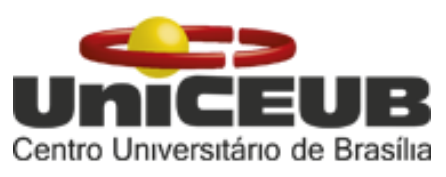

LUIZA RESENDE LARA GABRIEL

MAITÊ LÔBO KOLARIK

DETECÇÃO DE LEGIONELLA SPP. EM FONTES DE ÁGUA DA COMUNIDADE EM BRASÍLIA, DISTRITO FEDERAL.

Relatório final de pesquisa de Iniciação Científica apresentado à Assessoria de Pós-Graduação e Pesquisa.

Orientação: Prof. Msc. Fabíola Fernandes dos Santos Castro.

\section{BRASÍLIA}




\section{Agradecimentos}

Gostaríamos de agradecer à querida professora Fabíola por orientar esse trabalho, às nossas famílias que entenderam e apoiaram mesmo com a nossa ausência dos eventos familiares, aos colegas que deram suporte moral e à Assessoria de Pós-Graduação e Pesquisa por disponibilizar as ferramentas que permitiram o melhoramento deste trabalho. 


\title{
DETECÇÃO DE LEGIONELLA SPP EM FONTES DE ÁGUA DA COMUNIDADE EM BRASÍLIA, DISTRITO FEDERAL.
}

\author{
Luiza Resende Lara Gabriel - UniCEUB, PIC voluntário \\ luizarlg@sempreceub.com
}

\author{
Maitê Lôbo Kolarik - UniCEUB, PIC voluntário \\ maite.kolarik@sempreceub.com
}

\author{
Fabíola Fernandes dos Santos Castro - UniCEUB, professor orientador \\ fabiola.castro@ceub.edu.br
}

Legionella é um bacilo gram-negativo não fermentador fastidioso responsável por causar doenças respiratórias de forma grave, como a pneumonia, acarretando na doença dos legionários, ou de forma mais branda como a febre de Pontiac. É uma bactéria de fonte ambiental que possui a água como seu principal reservatório e, sua transmissão ocorre por meio da inalação de aerossóis de fontes de água contaminada. Por não existirem pesquisas ambientais prévias em Brasília, Distrito Federal, a respeito da presença desse microorganismo em fontes de água da comunidade, esse tema foi selecionado para a realização da pesquisa em locais públicos onde se tem grande circulação de pessoas. O objetivo deste trabalho foi pesquisar e identificar possíveis fontes de Legionella spp. em água de ambientes comunitários de Brasília, DF. Foram selecionados pontos de coleta onde houvesse grande circulação de pessoas. Para a realização das atividades propostas, foram coletadas 24 amostras de 1 litro de água em recipiente de polipropileno estéril. Para fontes de água tratadas com cloro, antes de sua análise foram adicionados $0,5 \mathrm{~mL}$ de solução a $0,1 \mathrm{M}$ de tiossulfato de sódio, e para as fontes não potáveis, foi necessário o tratamento com ácido fornecido pelo kit Legionelabac (Probac). Após homogeneização dos frascos, as amostras foram filtradas utilizando filtros de celulose de 0,22 $\mu \mathrm{m}$ (Unifil), transferidos para tubos cônicos estéreis com $5 \mathrm{~mL}$ de água destilada e agitadas em vórtex por 1 minuto. Após agitação, essas amostras foram inoculadas nas 3 faces do laminocultivo presente no kit Legionelabac (Probac) contendo ágar BCYE, seletivo para Legionella, e incubado a $37^{\circ} \mathrm{C}$ por 14 dias. A análise do crescimento das colônias, bem como suas características cromogênicas e as tintoriais nas colorações de Gram e Giemsa, confirmou-se a presença da bactéria em duas amostras (8,33\%). Em conclusão, foi possível perceber que o tratamento da água nem sempre é totalmente eficiente, alertando a população sobre os possíveis riscos oferecidos e retratando a necessidade de um controle microbiológico da água mais eficaz para esse micro-organismo. Também identificamos a oportunidade para novas pesquisas a respeito do tipo de Legionella encontrada, o que não foi possível realizar devido à limitação dos testes utilizados, pouco disponíveis no Brasil.

Palavras-Chave: Legionella spp. Água. Comunidade. Legionelose. 
SUMÁRIO

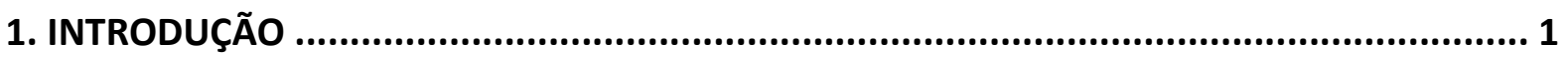

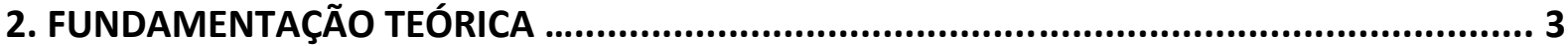

3. METODOLOGIA

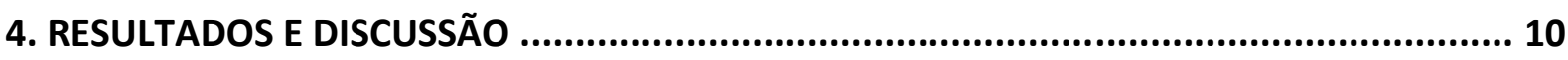

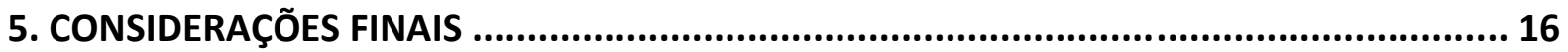

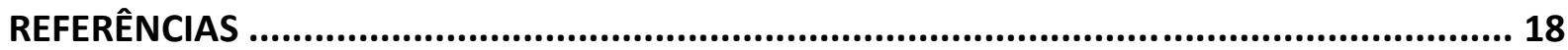




\section{INTRODUÇÃO}

Legionellaceae é uma família de bactérias Gram-negativas fastidiosas, não fermentadora de carboidratos, aeróbicas, não formadora de esporos, com formato de bastonetes (bacilos) responsáveis por causar a doença dos legionários, um tipo de pneumonia grave, ou a febre de Pontiac, uma infecção com sintomas parecidos com o da gripe, sendo portanto, menos grave. A Legionella pneumophila é considerada a espécie de maior relevância (MERCANTE; WINCHELL, 2015).

Seu gênero é composto por 50 espécies e 70 sorogrupos, sendo 16 deles pertencentes a L. pneumophila (WHO, 2007). Na Europa, cerca de $70 \%$ das infecções causadas por essas bactérias são causadas pela L. pneumophila sorogrupo 1, 20\% pelos outros sorogrupos e, 10\% por espécies de Legionella não-pneumophilas (JOSEPH, 2002).

Dentre os casos de legionelose causados por espécies não pneumophilas se encontram a L. bozemanii e a L. micdadei, como maior parte dentro desse grupo, sendo essa última um agente etiológico comum em causar a doença dos legionários em pacientes imunocomprometidos, logo após a L. pneumophila (REINGOLD et al., 1984; FANG; YU; VICKERS, 1989).

São consideradas bactérias de fontes ambientais, as quais são encontradas em água, ambientes úmidos e no solo, mas também podem habitar, de forma intracelular, alguns parasitas, dentre eles as amebas. Sua transmissão ocorre por meio de partículas aerossolizadas provenientes da água ou do solo, ainda não sendo descrita a forma direta do contato de pessoa para pessoa (SCHULZ et al., 2005).

Uma das principais fontes desencadeadoras dessa doença é a água, devido a diversos fatores como, por exemplo, erros na filtração, bem como falhas nesse processo ou falta de programas de tratamento contra Legionella spp (CDC, 2017).

A água parada favorece a formação de biofilmes, comunidades microbianas que se aderem umas às outras em superfícies bióticas ou abióticas. A L. pneumophila consegue se aderir à superfícies in vitro e in situ em diferentes materiais plásticos usados em encanamentos e também em fontes de carbono, o qual fornece os nutrientes necessários para o seu crescimento. Além disso, alguns íons tais como o cálcio e o magnésio parecem facilitar a formação dessas comunidades em superfícies abióticas, já o zinco em alta concentração além de também aumentar a capacidade de fixação da bactéria favorece a 
ligação com células do hospedeiro, como por exemplo as do pulmão, enquanto o cobre impede essa aderência (ABDEL-NOUR et al., 2013).

Essas bactérias são capazes de sobreviver na presença de cloro, geralmente utilizado para tratar água e, possuem maior facilidade de causar infecções em pacientes imunocomprometidos. Os humanos são hospedeiros nos quais ao serem infectados por meio da via respiratória, macrófagos alveolares promovem a fagocitose desse microorganismo, os quais agem em seu interior impedindo a fusão fagolisossomal e se multiplicam até romper sua membrana, tendo como resposta de defesa do corpo, a febre (KONEMAN, 2014).

Ao entrar em contato com esse patógeno, pode haver desenvolvimento de dois tipos de manifestações clínicas, a febre de Pontiac, com sintomas mais brandos, como mialgia, mal-estar, cefaleia e febre, possuindo curta duração, ou desencadear a doença dos legionários, gerando tosse, mialgia, cefaleia, febre e dificuldades respiratórias, podendo ser associada com diarréia, náusea e confusão mental (CDC, 2017).

A pneumonia adquirida na comunidade (PAC) é uma inflamação a qual compromete as vias aéreas, possuindo origem viral, bacteriana ou fúngica, sendo contraída fora do meio hospitalar e podendo surgir em até 48 horas da entrada do paciente, as quais geram alterações no parênquima pulmonar (CORRÊA et al. , 2009).

A PAC possui diversos agentes causadores e, dentre uns dos mais frequentes, encontra-se a Legionella pneumophila, causando a doença dos legionários, a qual observa-se sua predominância em pacientes do sexo masculino acima de 50 anos, com sinais e sintomas comuns a outras doenças, tais como tosse, bronquite e infecções do trato respiratório inferior (MARCHELLO et al, 2016) .

Para realização do diagnóstico laboratorial dessa doença, o método mais eficiente é a cultura das amostras de escarro, broncoscopia, aspirado transtraqueal, líquido pleural, aspirados pulmonares ou biópsia de pulmão, que são semeadas em ágar BCYE, mais recomendado para o crescimento de legionelas, e também a detecção do antígeno na urina, sendo esse o método mais utilizado na prática, principalmente se o paciente não possuir tosse acompanhada de secreção, ou tiver outras patologias em que não seria viável a coleta de escarro. Além desses métodos, o teste sorológico também pode ser utilizado como 
procedimento complementar, coletando amostras de sangue na fase aguda, para assim detectar anticorpos contra esse micro-organismo (FIELDS; BENSON; BESSER, 2002).

A doença dos legionários pode ter diversas complicações, principalmente as pulmonares e, por isso ela deve ser diagnosticada da forma mais rápida possível e tratada com antibióticos, tais como eritromicina, rifampicina associada com doxiciclina ou trimetoprim-sulfametoxazol, a fim de evitar o óbito do paciente (SCHULZ et al., 2005).

O objetivo deste trabalho foi pesquisar e identificar possíveis fontes de Legionella spp. em água de ambientes comunitários de Brasília, DF. Os objetivos específicos foram identificar Legionella spp. patogênicas em amostras de água da comunidade onde há grande circulação de indivíduos, identificar se há presença da espécie de Legionella de maior frequência, conhecida como Legionella pneumophila e, relacionar os dados obtidos com estudos semelhantes no Brasil e exterior.

\section{FUNDAMENTAÇÃO TEÓRICA}

\section{Histórico}

Em 1976, houve um surto de pneumonia na Filadélfia, que obteve 182 casos documentados, por um patógeno ainda desconhecido, o qual causou diversas mortes, inclusive em anos anteriores que, até então não se conhecia a causa. Em 1977, esse patógeno foi isolado, mas apenas em 1979 ele foi identificado e denominado como Legionella pneumophila, sendo classificado na família Legionellaceae, uma família de bactérias Gram-negativas em formas bacilares. Essa doença foi nomeada de doença dos legionários e possuía manifestações sistêmicas, porém apresentava a pneumonia como um dos sintomas mais dominantes (KONEMAN, 2014).

No Brasil, o primeiro caso de isolamento dessa bactéria foi em um paciente que possuía a Síndrome da Angústia Respiratória do Adulto (SARA) em unidade de terapia intensiva e, apresentava evolução prolongada. Sua confirmação foi obtida por meio da titulação de anticorpos no soro, com amostra sanguínea colhida durante a fase aguda da doença. Mesmo a Legionellaceae possuindo mais de 40 espécies e diversos sorogrupos, a $L$. pneumophila, sorogrupos 1 e 6, é responsável pela maioria dos casos da doença dos legionários (VERONESI, 2015). 


\section{Epidemiologia da doença}

A legionelose é uma doença respiratória causada pela inalação de aerossóis provenientes de água ou solo ou por meio da aspiração de água contendo a bactéria Legionella que, ao entrar no corpo através desses mecanismos, se direciona para os pulmões e se multiplica em macrófagos alveolares, caracterizando assim um quadro de pneumonia e possível bacteremia (MERCANTE; WINCHELL, 2015).

Essa doença pode ter diversas complicações, principalmente as pulmonares e, por isso ela deve ser diagnosticada da forma mais rápida possível e tratada com antibióticos, tais como eritromicina, rifampicina associada com doxiciclina ou trimetoprim-sulfametoxazol, a fim de evitar o óbito do paciente (SCHULZ et al., 2005).

Fontes de água geralmente apresentam boa condição para o crescimento de legionelas, por apresentarem temperatura e $\mathrm{pH}$ necessários para seu crescimento, estando entre 20 e 50 graus Celsius e pH de 5 e 8, respectivamente. Portanto, equipamentos aerossolizados contendo água, se mostram como um grande fator de risco para a população (FERREIRA; CUNHA, 2007).

Nos Estados Unidos da América (EUA), Canadá, Nova Zelândia, Austrália, Japão, Singapura e Europa, as legioneloses (tanto doença dos legionários quanto febre de Pontiac) são doenças de notificação compulsória e ficam sob programas de vigilância. No entanto, a dificuldade de se diagnosticar o patógeno faz com que os dados sejam subnotificados nos demais países. Na Europa, os países com maiores números de caso são: França, Itália e Espanha. Nos EUA, a incidência de legioneloses aumentou de 3,9 a 11,5 por milhão de habitantes entre 2000 e 2009 (PHIN et al., 2014).

Herwaldt e Marra (2018) estimam que o número de pacientes hospitalizados com Doença dos Legionários nos Estados Unidos é entre 8 e 18 mil pacientes por ano, com um custo de tratamento entre 26 e 40 mil dólares, tendo em vista que esses pacientes permanecem internados por, em média, 10 dias, acometendo com frequência pacientes transplantados.

A crise de água na cidade de Flint (EUA) entre 2014 e 2015 foi o terceiro maior surto nos Estados Unidos de Doença dos Legionários, associadas a mudança da fonte e do tratamento de água que abastecia o Condado de Genesee em Michigan. A água tratada que antes era comprada do Departamento de Água e Esgoto de Detroit (DAED) fora substituída 
pelo tratamento local das águas do rio Flint. Além de relatos da população de sintomas de erupções cutâneas e mudança de odor e cor da água, houve a detecção de coliformes fecais no sistema de distribuição de água. Dentro de semanas, o número de casos de DL aumentou, principalmente durante o verão de 2015. Após diversas reclamações da população, o condado voltou a comprar água da DAED e o número de casos retrocedeu. Apesar da alteração da água ser multiparamétrica, Zahran e colaboradores (2018) associaram a alteração na qualidade da água decorrentes do resíduo de cloro livre como responsável pelo surto de Doença dos Legionários.

No período de 2007 a 2008, foram realizadas pesquisas no Brasil, relacionando a presença da bactéria Legionella em diversas amostras de água. Em São Paulo, foram coletadas um total de 69 amostras provenientes de residências, edifícios públicos e hospitais e, dentre elas, 6 foram positivas, já no Rio de Janeiro, foram investigadas amostras de água de hospitais em que todos os resultados deram positivos, mostrando assim possíveis riscos para a população e, portanto, para a saúde pública, visto que sua disseminação ocorre por partículas aerossolizadas (ETTO; RAZZOLINI, 2011).

Na América do Norte, durante o intervalo do ano de 2000 até 2014, houve um aumento de $\mathbf{2 8 6 \%}$ no número de notificações relacionadas a legionelose por diversas causas, estando geralmente associadas a fontes de água em diversos locais, tais como hotéis, cruzeiros, torres de refrigeração, termas e hospitais contaminados em sua maioria pela Legionella pneumophila. Em 2011-2012, houve registro de 21 casos com 14 mortes relacionadas a presença da Legionella em água potável (GARRISON et al., 2016).

Nos anos de 2009-2010, 11.856 casos foram notificados na Europa, tendo como destaque a Eslovênia em 2009 e a Holanda em 2010, devido a legionelose e, para a maioria deles, a fonte era conhecida, sendo elas relacionadas a comunidade, viagens ou problemas de saúde (imunocomprometimento). Dentre esses casos, 43\% possuíam 65 anos ou mais, 73\% eram homens e 85\% dos 1.166 casos eram referentes a L. pneumophila (BEAUTÉ; ZUCS; JONG, 2013).

A distribuição de sexo e idade dos pacientes é similar em todos os países, sendo que a maioria dos casos ocorre em pacientes com mais de 50 anos (74-91\%), predominando em homens. A Doença dos Legionários costuma ter um pico do final do verão para começo do inverno, com clima mais quente e úmido. Na Austrália e na Nova Zelândia, os casos são mais 
frequentes ocorrem na primavera, por L. longbeachae, supostamente relacionado aos adubos utilizados em atividades de jardinagem (PHIN et al., 2014).

\section{Pneumonia Adquirida na Comunidade}

Segundo Corrêa, et al. (2009), a Pneumonia Adquirida na Comunidade (PAC) é uma doença infecciosa aguda de maior impacto médico e social, tanto em relação à morbidade quanto aos custos relacionados ao tratamento.

Os principais agentes etiológicos bacterianos relacionados à pneumonia são Streptococcus pneumoniae, Chlamydophila pneumoniae, Mycoplasma pneumoniae, sendo esses os de maior predominância e, Haemophilus influenzae, Moraxella catarrhalis e L. pneumophila, com menor frequência no âmbito geral (BROWN, 2012).

No Brasil, a pneumonia encontra-se entre as primeiras causas de mortalidade relacionadas à doenças do trato respiratório e, tem a L. pneumophila como causa estimada de $6 \%$ desses casos (FERREIRA; CUNHA, 2007).

Exames de raio $\mathrm{X}$ de tórax demonstrando opacidade e outras manifestações sistêmicas como confusão mental, cefaleia, sudorese, calafrios, mialgias e temperatura corporal superior a $37,8^{\circ} \mathrm{C}$ são representativos da pneumonia, no entanto, outras doenças podem se manifestar clinicamente de forma semelhante, dificultando o diagnóstico apropriado (CORRÊA et al. , 2009).

Os pacientes que possuem seu diagnóstico de PAC confirmado devem ser avaliados, para assim classificar a gravidade da doença antes do início do tratamento. Essa classificação se dá por meio de dois tipos de escores, o primeiro "Pneumonia Severity Index" (PSI) avaliando características demográficas, comorbidades e exames físicos, podendo ser necessária a utilização de exames laboratoriais e, portanto não sendo o mais prático para a rotina, e o segundo, denominado CURB-65, que se baseia na presença de sinais frequentes, tais como confusão mental, ureia acima de $50 \mathrm{mg} / \mathrm{dL}$, frequência respiratória maior ou igual a 30 irpm, pressão arterial sistólica menor que $90 \mathrm{mmHg}$ ou diastólica menor ou igual a 60 $\mathrm{mmHg}$ e na idade acima de 65 anos, porém sua limitação é o fato de não incluir doenças associadas, as quais aumentam o risco de levar a óbito (PINHEIRO; OLIVEIRA, 2006).

Além dos escores previamente citados, existem outros como o COP-SMART, utilizado para prognosticar a necessidade de tratamentos agressivos, suporte ventilatório e 
internações em unidades de terapia intensiva, o SOAR, preditor de mortalidade aplicado especificamente em pacientes idosos, o qual avalia pressão arterial, idade maior de 65 anos e frequência respiratória e, o PIRO, também analisando a mortalidade, porém de crianças com a PAC, avaliando a predisposição, hipotensão e bacteremia, o mecanismo de resposta e se possui alguma disfunção de órgãos (UWAEZUOKE; AYUK, 2017).

\section{Epidemiologia da Pneumonia no DF}

No período de janeiro de 2008 até dezembro de 2016, a maior causa de internação registrada no DF foi "Gravidez, parto e puerpério" (445.684 internações), seguida por "Lesões, envenenamento e algumas outras conseqüências de causas externas" (151.903 internações) e por "Doenças do Aparelho Respiratório", com 146.800 internações, dentre elas, a pneumonia foi a causa mais frequente, com 75.872 internações (51\%). Em relação aos óbitos, as "Doenças do Aparelho Respiratório" foram a segunda causa mais comum de óbitos (8.589), atrás somente das "Doenças do Aparelho Circulatório" (11.088 óbitos). Dos óbitos causados por "Doenças do Aparelho Respiratório", 5.120 óbitos (59\%) foram causados por pneumonia (SIH/SUS, 2016).

Tabela 1: Média mensal do número de internações por pneumonia no Distrito Federal de 2008 a 2016.

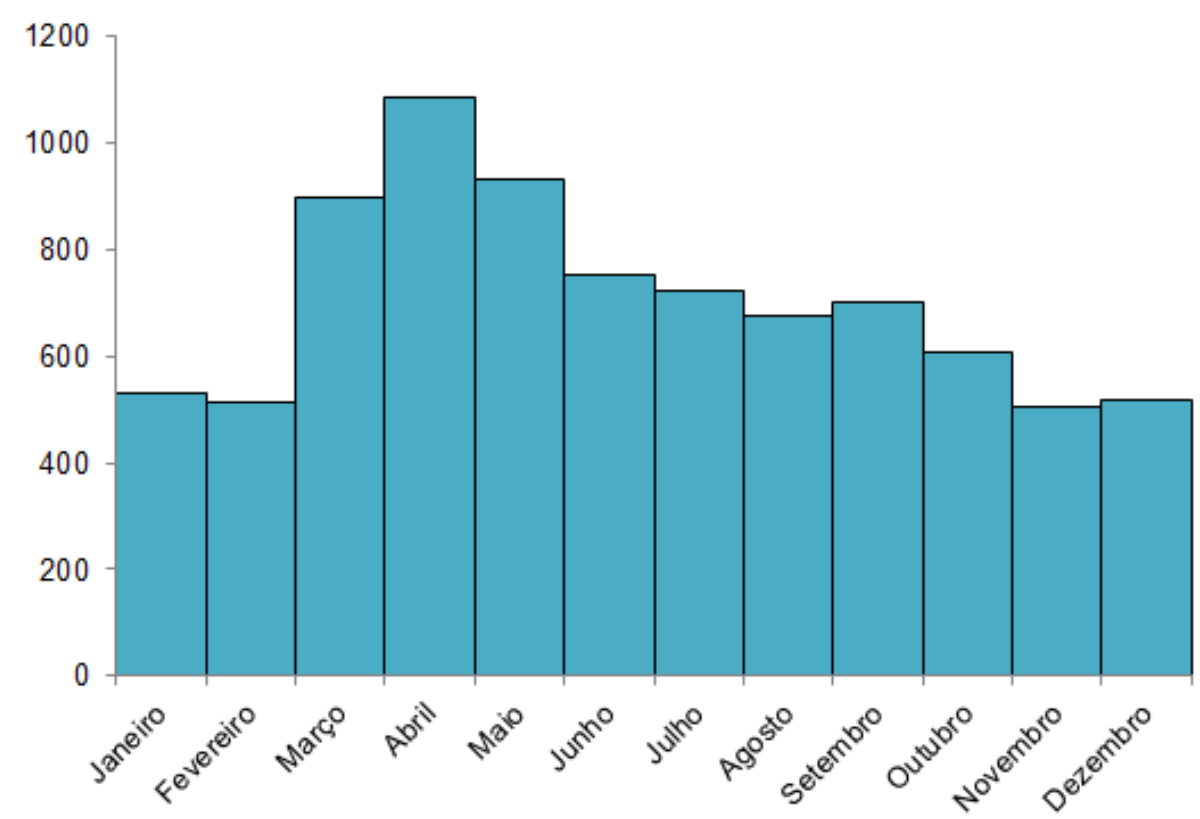

Fonte: BRASIL, 2017. 
Segundo Corrêa (2009), com o decorrer do tempo, as taxas de internação tem diminuído, mas a taxa de mortalidade mostra uma tendência ascendente, que pode ser explicada pelo aumento da internação de casos mais graves e pelo envelhecimento da população.

\section{METODOLOGIA}

Para alcançar os objetivos traçados para esta pesquisa, foi selecionado o tipo de estudo experimental, ou seja, de bancada na área de microbiologia e, com saída de campo para realizar a coleta das amostras utilizadas. O plano de trabalho foi dividido em seis etapas: estudo mais aprofundado sobre Legionella spp., coleta de amostras, avaliação e preparo das mesmas, semeio em meios de cultura, visualização microscópica, análise e interpretação dos resultados e divulgação do trabalho.

Para isso, as tarefas foram divididas entre as 2 pesquisadoras em um cronograma de atividades semanais diferentes, tendo início com estudos sobre métodos de diagnóstico de para a bactéria estudada em fontes de água e estudo a respeito de micro-organismos naturais de amostras de água, dando continuidade nas semanas seguintes com estudos sobre bactérias causadoras de pneumonia, bem como sua importância clínica e coleta de dados sobre antibióticos de uso na conduta médico-terapêutica. Após isso, foi estudado a respeito do tratamento das amostras e realizou-se a coleta das mesmas nos locais pré selecionados, logo em seguida essas amostras foram processadas e semeadas no meio de cultivo denominado ágar BCYE. Com a análise semanal desses cultivos, bem como as características morfológicas e cromogênicas das colônias, pôde-se realizar a interpretação dos resultados com o auxílio das colorações de Gram e Giemsa e cultura em ágar sangue, para assim confirmar os resultados. Por fim, nas últimas semanas foram confeccionadas planilhas com os resultados obtidos e elaborado o relatório final do trabalho.

Os locais foram definidos com base no alto fluxo de pessoas, sendo escolhidos assim, regiões públicas como: Parque da cidade, lago Paranoá, museu da Biblioteca Nacional (parte externa), rodoviária do Plano Piloto, torre de TV, Congresso Nacional (parte externa espelho d'água), Itamaraty (parte externa - espelho d'água), memorial JK (parte externa espelho d'água), Tribunal de Justiça do Distrito Federal e Territórios (TJDFT) (parte externa espelho d'água), Palácio da Justiça (parte externa- espelho d'água), Buriti (parte externa- 
espelho d'água), praça dos cristais, CCBB e UnB. As coletas foram realizadas entre março e abril de 2018.

Para a coleta das amostras, foi utilizada a técnica descrita pelo CDC em 2005, utilizando um frasco de polipropileno e coletando 1,0 L das amostras de água. Nas amostras em que a água era tratada com cloro, foi adicionado $0,5 \mathrm{~mL}$ de solução a $0,1 \mathrm{M}$ de tiossulfato de sódio para cada litro. Para coletas em torneiras, foi realizada a higienização com álcool 70\% e, em seguida, a torneira foi completamente aberta, escoando água por três minutos. Com o frasco coletor aberto, evitando tocar o bocal e a tampa em qualquer superfície, o frasco foi segurado verticalmente, até ser preenchido e fechado imediatamente após.

Para coletas em águas superficiais, o frasco foi segurado pela base e mergulhado com a boca para baixo rapidamente e inclinado um pouco para cima, contra a corrente ou movimentando-o para frente na direção horizontal até ser preenchido e fechado imediatamente após. As amostras foram transportadas refrigeradas até o UniCEUB, local de seu processamento.

Em amostras de água tratada com cloro, para aumentar a concentração das bactérias, foi necessário utilizar filtro de celulose com poros de $0,2 \mu \mathrm{m}$ para filtrar todo o volume da amostra. Em seguida, o filtro foi colocado em tubo Falcon de $15 \mathrm{~mL}$ estéril e vortexado por 1 minuto. Essa amostra foi inoculada nas três faces do laminocultivo e incubada a $37^{\circ} \mathrm{C}$.

Para as amostras não tratadas com cloro, foi realizado o tratamento com ácido, fornecido pelo kit Legionelabac, visando reduzir as demais bactérias presentes na amostra que não são de interesse para isolamento. Como a Legionella spp. é resistente a meios com pH baixo, não há interferência. Após 15 minutos de repouso em temperatura ambiente, foi adicionado a um tubo graduado estéril ( $15 \mathrm{~mL}) 1 \mathrm{~mL}$ da água coletada e $1 \mathrm{~mL}$ da solução ácida do kit para assim, inocular nas três faces do laminocultivo e incubar a $37^{\circ} \mathrm{C}$. A leitura dos laminocultivos foi realizada após $48 \mathrm{~h}$ e diariamente

Após a análise dos laminocultivos, foram realizados testes confirmatórios para verificar se às colônias que cresceram eram de fato o nosso alvo. Para tal, foi feito o repique das colônias em ágar sangue, coloração de Gram e nas duas últimas amostras suspeitas, coloração de Giemsa. 


\section{RESULTADOS E DISCUSSÃO}

Os resultados obtidos a partir dessa pesquisa utilizando essa metodologia foram: das 24 amostras coletadas, 17 (70,8\%) apresentaram crescimento. Destes, 5 (20,83\%) apresentaram características sugestivas e foram repicados em ágar sangue sendo que 2 (8,33\%) apresentaram crescimento, sendo descartada a hipótese de ser Legionella (Quadro $1)$.

Quadro 1: Pontos de coleta de água para a pesquisa resultados obtidos.

\begin{tabular}{|c|c|c|c|c|}
\hline Amostra & $\begin{array}{l}\text { Local de coleta } \\
\text { da amostra }\end{array}$ & $\begin{array}{l}\text { Crescimento } \\
\text { em BCYE }\end{array}$ & $\begin{array}{c}\text { Côlonias } \\
\text { características? }\end{array}$ & Testes confirmatórios \\
\hline 1 & $\begin{array}{c}\text { Chuveiro parque } \\
\text { da cidade }\end{array}$ & Sim & Não & - \\
\hline 2 & $\begin{array}{c}\text { Bebedouro } \\
\text { parque da cidade }\end{array}$ & Sim & Não & - \\
\hline 3 & $\begin{array}{c}\text { Banheiro } \\
\text { feminino parque } \\
\text { da cidade }\end{array}$ & Sim & Não & - \\
\hline 4 & $\begin{array}{l}\text { Banheiro } \\
\text { rodoviária }\end{array}$ & Sim & Não & - \\
\hline 5 & $\begin{array}{c}\text { Banheiro Pontão } \\
\text { do Lago Sul }\end{array}$ & Sim & Não & - \\
\hline 6 & $\begin{array}{l}\text { Espelho d'agua } \\
\text { Pontão }\end{array}$ & Não & Não & - \\
\hline 7 & $\begin{array}{l}\text { Lago parque da } \\
\text { cidade }\end{array}$ & Não & Não & - \\
\hline 8 & Lago Paranoá & Não & Não & - \\
\hline 9 & $\begin{array}{c}\text { Fonte torre de } \\
\text { TV }\end{array}$ & Sim & Não & - \\
\hline 10 & $\begin{array}{l}\text { Espelho d'água } \\
\text { museu biblioteca } \\
\text { nacional }\end{array}$ & Sim & Não & - \\
\hline 11 & $\begin{array}{l}\text { Espelho d'água } \\
\text { Congresso } \\
\text { Nacional }\end{array}$ & Sim & Sim & $\begin{array}{l}\text { Gram não característico } \\
\text { de bacilos Gram } \\
\text { negativos. }\end{array}$ \\
\hline
\end{tabular}




\begin{tabular}{|c|c|c|c|c|}
\hline & & & & $\begin{array}{l}\text { Crescimento em ágar } \\
\text { sangue. }\end{array}$ \\
\hline 12 & $\begin{array}{l}\text { Espelho d'água } \\
\text { Itamaraty }\end{array}$ & Sim & $\begin{array}{l}\text { Sim, colônias } \\
\text { brilhantes. }\end{array}$ & $\begin{array}{l}\text { Gram característico de } \\
\text { bacilos Gram negativos. } \\
\text { Não houve crescimento } \\
\text { em ágar sangue. } \\
\text { Giemsa sugestivo de } \\
\text { bacilos. }\end{array}$ \\
\hline 13 & $\begin{array}{l}\text { Espelho d'água } \\
\text { Palácio da Justiça }\end{array}$ & Sim & $\begin{array}{l}\text { Sim, colônias } \\
\text { brilhantes. }\end{array}$ & $\begin{array}{l}\text { Gram não característico } \\
\text { de bacilos Gram } \\
\text { negativos. } \\
\text { Não houve crescimento } \\
\text { em ágar sangue. }\end{array}$ \\
\hline 14 & $\begin{array}{l}\text { Espelho d'água } \\
\text { memorial JK }\end{array}$ & Sim & Sim & $\begin{array}{l}\text { Gram não característico } \\
\text { de bacilos Gram } \\
\text { negativos. } \\
\text { Não houve crescimento } \\
\text { em ágar sangue. }\end{array}$ \\
\hline 15 & $\begin{array}{l}\text { Espelho d'água } \\
\text { TJDF }\end{array}$ & Sim & $\begin{array}{l}\text { Sim, colônias } \\
\text { brilhantes. }\end{array}$ & $\begin{array}{l}\text { Gram característico de } \\
\text { bacilos Gram negativos. } \\
\text { Não houve crescimento } \\
\text { em ágar sangue. } \\
\text { Giemsa sugestivo de } \\
\text { bacilos. }\end{array}$ \\
\hline 16 & $\begin{array}{c}\text { Espelho d'água } \\
\text { praça } \\
\text { TJDF/Buritis }\end{array}$ & Sim & Não & - \\
\hline 17 & $\begin{array}{l}\text { Praça dos } \\
\text { Cristais }\end{array}$ & Sim & Não & - \\
\hline 18 & Lago Zoológico & Sim & Não & - \\
\hline 19 & $\begin{array}{l}\text { Bebedouro } \\
\text { Zoológico }\end{array}$ & Não & Não & - \\
\hline 20 & $\begin{array}{l}\text { Banheiro } \\
\text { feminino } \\
\text { Zoológico }\end{array}$ & Não & Não & - \\
\hline 21 & Bebedouro CCBB & Não & Não & - \\
\hline
\end{tabular}




\begin{tabular}{|c|c|c|c|l|}
22 & $\begin{array}{c}\text { Banheiro } \\
\text { feminino CCBB }\end{array}$ & Não & Não & - \\
\hline 23 & $\begin{array}{c}\text { Bebedouro ICC- } \\
\text { UNB }\end{array}$ & Sim & Não & - \\
\hline 24 & $\begin{array}{c}\text { Banheiro ICC- } \\
\text { UNB }\end{array}$ & Sim & Não & - \\
\hline
\end{tabular}

Fonte: elaborado pelas autoras.

Para os demais, foi feita a coloração de Gram, mas apenas $2(8,33 \%)$ apresentaram coloração característica de bacilos Gram negativos (figuras 2 e 5) e, então foi realizada a coloração de Giemsa (figuras 3 e 6), confirmando o achado.

O meio de cultivo ideal para o crescimento desse micro-organismo deve conter extrato de levedura para fornecer os nutrientes, e carvão ativado, o qual remove radicais de oxigênio, pois são gerados por meio da exposição do meio a luz e são tóxicos. A identificação do crescimento em ágar BCYE e a ausência do crescimento em ágar sangue são prováveis indicativos de Legionella, as quais se mostram de formato puntiforme ou até $4 \mathrm{~mm}$, sendo brilhantes, convexas e circulares (figuras 1a, 1b, 4a e 4b) (KONEMAN, 2008).

Figura 1 (a e b): Amostra 12 em laminocultivo com meio BCYE (a) e meios seletivos (b) (específico para Legionella à esquerda).

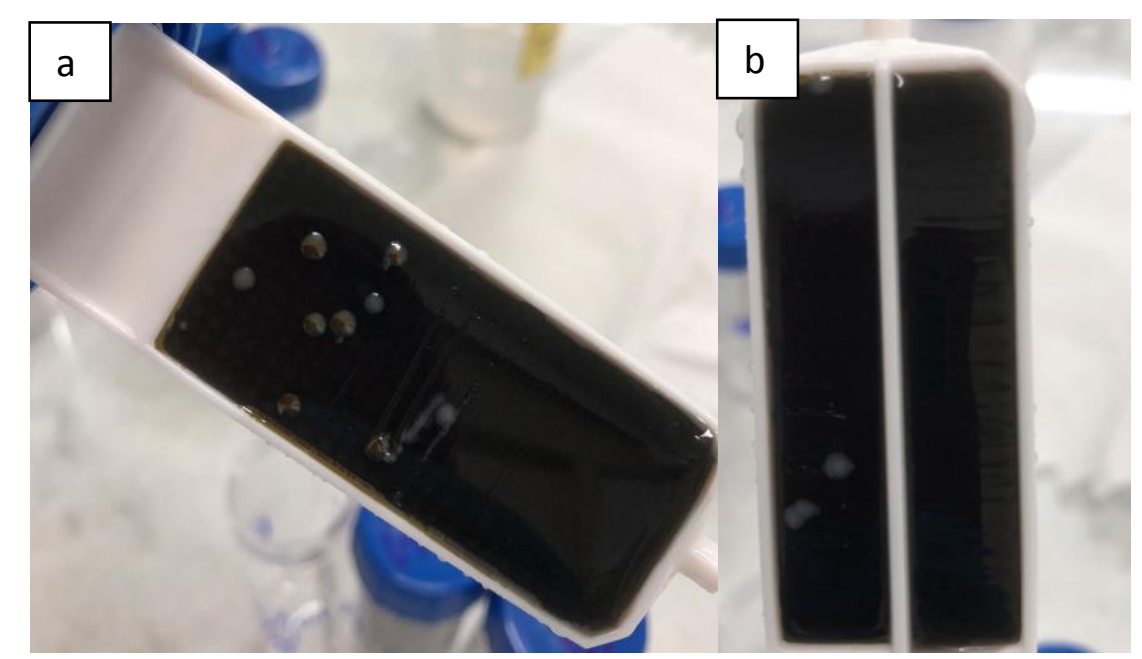

Fonte: GABRIEL; KOLARIK, 2018. 
Figura 2: Coloração de Gram da amostra 12.

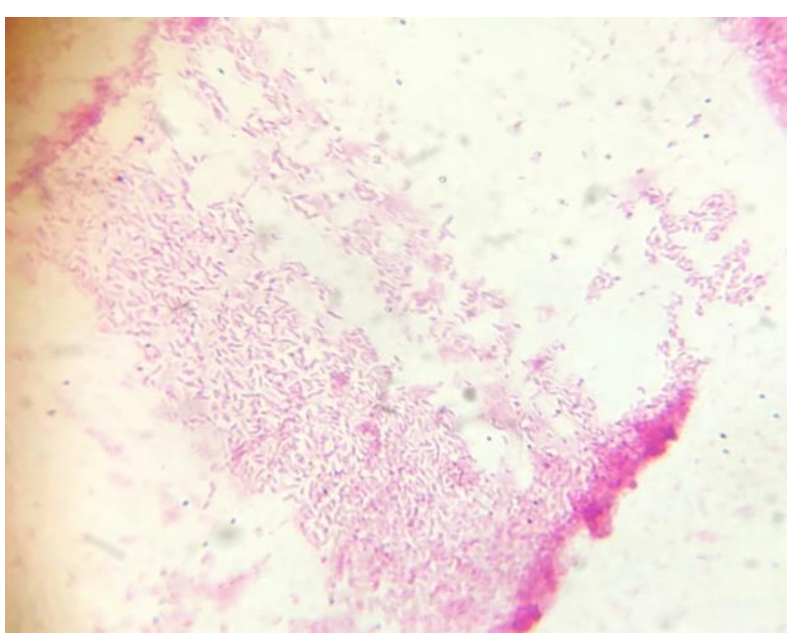

Fonte: GABRIEL; KOLARIK, 2018.

Figura 3: Coloração de Giemsa da amostra 12.

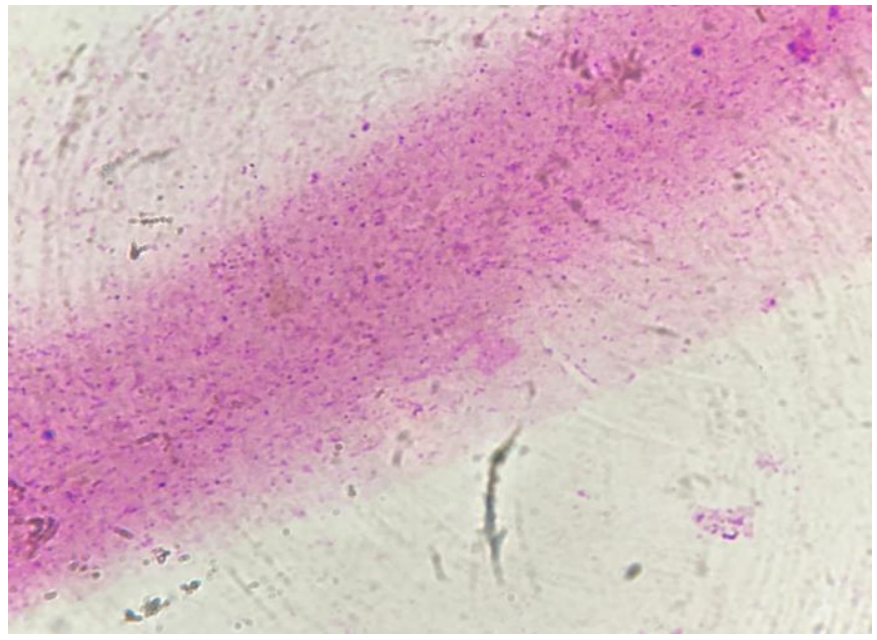

Fonte: GABRIEL; KOLARIK, 2018. 
Figura 4: Amostra 15 em laminocultivo com meio BCYE (a) e meios seletivos (b) (específico para Legionella abaixo).

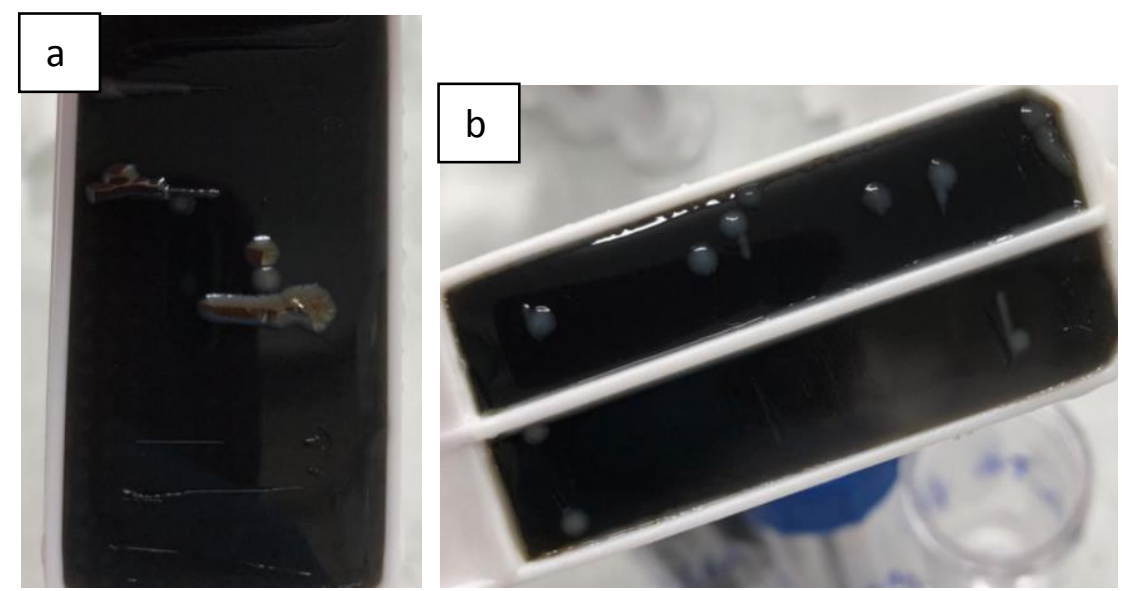

Fonte: GABRIEL; KOLARIK, 2018.

Figura 5: Coloração de Gram da amostra 15.

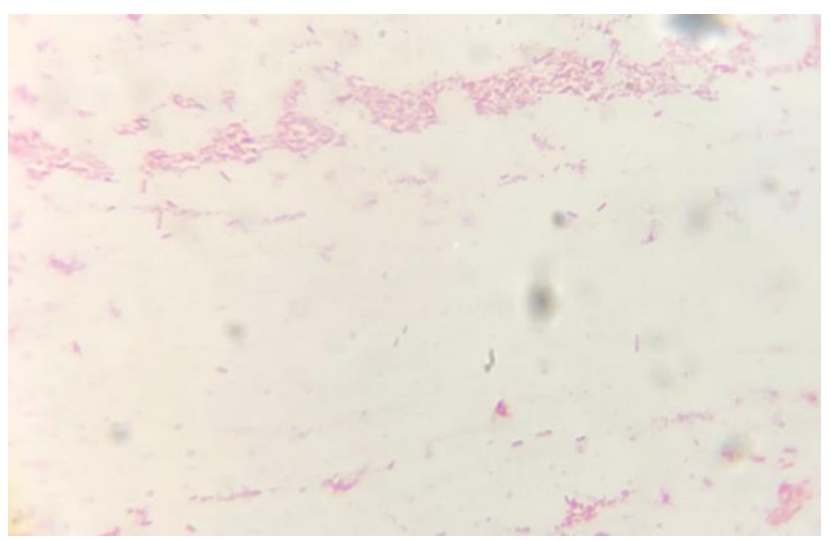

Fonte: GABRIEL; KOLARIK, 2018.

Figura 6: Coloração de Giemsa da amostra 15.

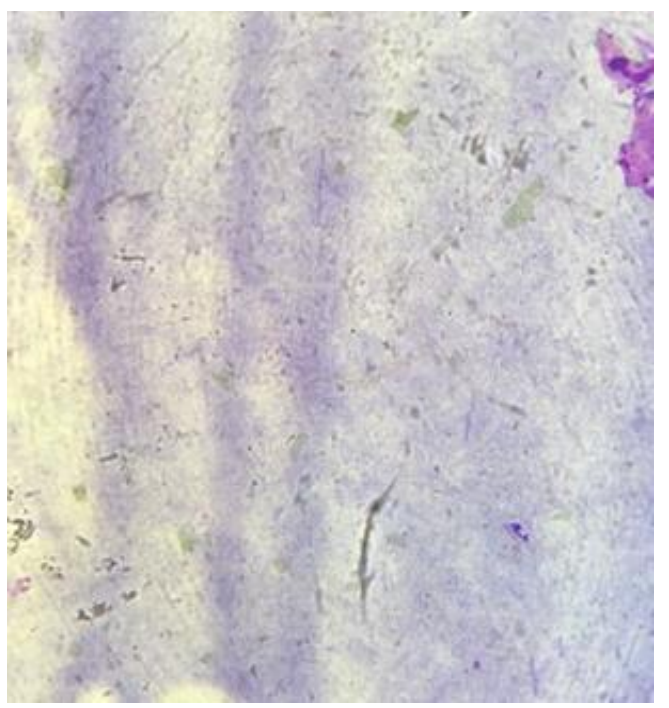

Fonte: GABRIEL; KOLARIK, 2018. 
Nossos achados foram similares aos encontrados por Carvalho, Foronda e Pellizari (2007), que pesquisaram a bactéria em 77 amostras de água e biofilme de reservatórios naturais e sistemas artificiais de climatização de ambientes interiores, encontrando Legionella pneumophila em 9 dessas amostras (11,7\%). Nesse estudo, os autores também sugeriram que a maior concentração de íons metálicos nos sistemas artificiais de água favorecem a ocorrência da bactéria, uma vez que eles não possuíram resultados positivos em reservatórios naturais.

A Legionella pneumophila foi isolada pela primeira vez no Brasil em 1989 por Gomes e colaboradores. Em 1991 foi relatado o primeiro surto de Doença dos Legionários na América Latina, em uma clínica de transplante renal em São Paulo, onde foi identificada Legionella anisa na água de torneira, provável fonte de infecção, uma vez que após tratamento com cloro e aquecimento da água, os casos cessaram (LEVIN et al., 1991).

Em estudo realizado por Chedid e colaboradores (2005) em um hospital universitário no Rio Grande do Sul entre 2000 e 2001 a incidência de pacientes com pneumonia adquirida na comunidade causada por L. pneumophila de sorogrupos 1-6 foi de 5.1\%.

No entanto, um estudo demonstrou que as pesquisas de pneumococos e Legionella na urina são solicitadas por menos de $1 / 3$ dos médicos que tratam pacientes com pneumonia adquirida na comunidade na Península Ibérica e na América Latina, reforçando que a Doença dos Legionários pode ser subdiagnosticada no Brasil (SALLUH et al., 2014).

Apesar do principal método para diagnóstico de Legionella ainda ser a cultura, o teste mais utilizado na prática é a pesquisa de antígenos na urina e, apesar dessa ferramenta ainda possuir sensibilidade e especificidade menor do que testes de biologia molecular, como a identificação por PCR (Polymerase Chain Reaction - Reação em Cadeia da Polimerase), esses testes moleculares de grande valor diagnóstico ainda não foram bem estabelecidos na rotina (HERWALDT; MARRA 2018).

No Brasil, Etto e Razzolini (2011) realizaram pesquisa de Legionella em sistemas de ar condicionado em ambiente hospitalar, e seus resultados (9,8\% das amostras positivas) evidenciaram que a manutenção negligenciada pode estar favorecendo a formação de biofilmes e colonização de bactérias patogênicas como a Legionella. Com isso, sugeriram o monitoramento e vigilância permanente de sistemas de ar condicionado, sendo importante principalmente em hospitais, onde há maior quantidade de pessoas imunocomprometidas. 
Em outro estudo realizado no Rio de Janeiro, Ferreira (2004) pesquisou a presença de Legionella pneumophila em 16 hospitais e detectou resultados positivos em 5 (31\%), demonstrando a importância da vigilância rotineira da distribuição de água em hospitais, inclusive para a L. pneumophila.

Em $85 \%$ dos surtos de Legionella investigados pelo CDC, pelo menos uma falha de manutenção de sistema de água foi identificada em cada surto, incluindo principalmente níveis inadequados de desinfetantes e temperatura ótima para o crescimento de Legionella (HERWALDT; MARRA, 2018).

Um ponto fraco do nosso estudo é a possibilidade de falsos negativos. Apesar da cultura de amostras de água ter boa sensibilidade, a baixa amostragem pode ter influenciado no nosso estudo. Técnicas mais sensíveis como a PCR quantitativa em tempo real (qPCR) tem alto valor preditivo negativo e baixo valor preditivo positivo, mas podem ser uma ferramenta útil para identificação mais rápida de possíveis fontes de contaminação e eliminar a possibilidade de outras (HERWALDT; MARRA 2018).

\section{CONSIDERAÇÕES FINAIS}

As legioneloses são doenças com incidência crescente e alta taxa de mortalidade. Os dados sobre essas doenças no Brasil são limitados e costumam ser menores em relação aos dados de países como Estados Unidos e países da Europa, provavelmente por serem subdiagnosticadas, uma vez que suas pesquisas são menos solicitadas pelos médicos e por terem métodos pouco disponíveis e/ou pouco sensíveis.

Ao finalizar a pesquisa e concluir o objetivo geral de pesquisar e identificar a bactéria Legionella em fontes de água da comunidade, foi possível perceber que o tratamento da água nem sempre é totalmente eficaz, alertando a população sobre os possíveis riscos oferecidos por fontes de água e a necessidade de um controle microbiológico com foco para esse micro-organismo.

Existe a grande necessidade de melhores metodologias para deteç̧ão desse patógeno em amostras clínicas e amostras de água, reforçando a necessidade de garantir tratamento de água adequado e prevenção dessas infecções, mesmo apresentando dificuldades da interpretação desse tipo de vigilância devido ao fato de não terem sido reportados a ocorrência de casos da doença. 
Também foi identificada a oportunidade de futuras novas pesquisas a respeito do tipo de Legionella encontrada, o que não foi possível realizar devido à limitação dos testes utilizados, pouco disponíveis no Brasil. 


\section{REFERÊNCIAS}

ABDEL-NOUR, M. et al. Biofilms: The Stronghold of Legionella pneumophila. International Journal of Molecular Sciences, v. 14, ed. 11, p. 21660-21675, 2013.

BEAUTÉ, J.; ZUCS, P.; JONG, B. Surveillance and outbreak reports - Legionnaires' disease in Europe, 2009-2010. Eurosurveillance, v. 18, no. 10, Mar. 2013.

BRASIL. Manual prático de análise de água - Fundação Nacional de Saúde. 4. ed. Funasa: Brasília, 2013.

BRASIL. SIH/SUS. Sistema de Informações Hospitalares do Sistema Único de Saúde Morbidade Hospitalar do SUS - por local de internação (Distrito Federal). Disponível em: <http://tabnet.datasus.gov.br/cgi/deftohtm.exe?sih/cnv/niDF.def>. Acesso em 05 maio 2017.

BROWN, J.S. Community-acquired pneumonia. Clinical Medicine, v. 12, n.6, p. 538-543, 2012.

CARVALHO, F. R. S.; FORONDA, A. S.; PELLIZARI, V. H. Detection of Legionella pneumophila in water and biofilm samples by culture and molecular methods from man-made systems in São Paulo - Brazil. Braz. J. Microbiol., São Paulo, v. 38, n. 4, p. 743-751, dez. 2007.

CDC. Legionella (Legionnaires' Disease and Pontiac Fever). Disponível em: <http://www.cdc.gov/legionella/index.html>. Acesso em: 05 maio 2017.

CDC. Processing Environmental Samples: CDC Laboratory Protocol. Atlanta, Jan. 2005. Disponível em: <https://www.cdc.gov/legionella/health-depts/inv-tools-cluster/lab-invtools/procedures-manual.pdf>. Acesso em: 05 maio de 2017.

CHEDID, M. B. F. et al. Community-acquired pneumonia by Legionella pneumophilaserogroups 1-6 in Brazil. Respiratory Medicine, v. 99, ed. 8, p. 966-975, ago. 2005.

CORRÊA, R. A. et al. Diretrizes brasileiras para pneumonia adquirida na comunidade em adultos imunocompetentes - 2009. Jornal Brasileiro de Pneumologia, v. 35, ed. 6, p. 574601, 2009.

ETTO, H. Y.; RAZZOLINI, M.T.P. Deteç̧ão de bactérias do gênero Legionella em amostras de água de sistemas de ar condicionado. Epidemiologia e Serviços de Saúde, v. 20, p. 557-564, 2011.

FANG, G. D., YU, V. L.; VICKERS, R. M. Disease due to the Legionellaceae (other than Legionella pneumophila). Medicine Baltimore, v. 68, ed. 2, p.116-132, 1989.

FERREIRA, A. P. CUNHA, C. L. N. Pesquisa de Legionella pneumophila nas redes de abastecimento hospitalar. Revista Eletrônica de Comunicação Informação \& Inovação em 
Saúde, Rio de Janeiro, v.1, n.2, p.208-214, 2007.

FERREIRA, A. P. Risk and management in hospital water systems for Legionella pneumophila: a case study in Rio de Janeiro - Brazil. International Journal of Environmental Health Research, v. 14, ed. 6, p. 453-459, 2004.

FIELDS, B.S.; BENSON, R.F.; BESSER, R.E. Legionella and Legionnaires' Disease: 25 Years of Investigation. Clinical Microbiology Reviews, v.15, no. 3, p. 506-526, jul. 2002.

GARRISON, L.E. et al. Vital Signs: Deficiencies in Environmental Control Identified in Outbreaks of Legionnaires' Disease - North America, 2000-2014. Morbidity and Mortality Weekly Report, CDC, 2016.

GOMES, J. C. P. et al. Legionella pneumophila associada a insuficiência respiratória aguda: primeiro isolamento no Brasil. Rev. Inst. Med. trop. S. Paulo, São Paulo, v. 31, n. 6, p. 368376, dez. 1989.

HERWALDT, L. A.; MARRA, A. R. Legionella: a reemerging pathogen. Current Opinion in Infectious Diseases, v. 31, ed. 4, p. 325-333, ago. 2018.

JOSEPH, C. Surveillance of Legionnaires disease in Europe. In: MARRE, R. et al. Legionella. Washington: ASM Press, 2002.

KONEMAN. Diagnóstico microbiológico: texto e atlas colorido. 6a. ed. Rio de Janeiro: Guanabara Koogan, 2014.

LEVIN, A. S. S. et al. An outbreak of nosocomial Legionnaires' disease in a renal transplant unit in São Paulo, Brazil. Journal of Hospital Infection, v. 18, ed. 3, p. 243-248, 1991.

MARCHELLO, C. et al. Prevalence of Atypical Pathogens in Patients With Cough and Community-Acquired Pneumonia: A Meta-Analysis. Annals of Family Medicine, v. 14.6, p. 552-566, nov. 2016.

MERCANTE, J.W.; WINCHELL, J.M. Current and Emerging Legionella Diagnostics for Laboratory and Outbreak Investigations. Clinical Microbiology Reviews, v. 28, n. 1, p. 95133, 2015.

PHIN, N. et al. Epidemiology and clinical management of Legionnaires' disease. The Lancet Infectious Diseases, v.14, ed. 10, p. 1011 - 1021, 2014.

PINHEIRO, B. V.; OLIVEIRA, J. C. A. Pneumonia adquirida na comunidade, Juiz de Fora, 2006. p. 12-14. Disponível em: <http://www2.unifesp.br/dmed/pneumo/Dowload/Pneumonia\%20Adquirida\%20na\%20Co munidade.pdf>. Acesso em 12 junho 2018. 
REINGOLD, A. L. et al. Legionella pneumonia in the United States: the distribution of serogroups and species causing human illness. Journal of Infectious Diseases, v. 149, ed. 5, 1984.

SALLUH, J. I. F. et al. Management of severe community-acquired pneumonia: A survey on the attitudes of 468 physicians in Iberia and South America. Journal of Critical Care, v. 29, ed.5, 743-747, 2014.

SCHULZ, D. et al. Doença dos Legionários: uma Revisão. Revista Brasileira de Análises Clínicas, vol. 37(4), p. 251-255, 2005.

UWAEZUOKE, S. N.; AYUK, A. C. Prognostic Scores and Biomarkers for Pediatric CommunityAcquired Pneumonia: How Far Have We Come?. Pediatric Health, Medicine and Therapeutics, v. 8, p. 9-18, 2017.

VERONESI R., FOCACCIA R. Tratado de Infectologia. 5a ed. São Paulo: Ed Atheneu, 2015.

World Health Organization (WHO). Legionella and the prevention of legionellosis, p. 19, 2007.

<http://www.who.int/water_sanitation_health/emerging/legionella.pdf $>$. Acesso em 12 junho 2018.

ZAHRAN, S. et al. Assessment of the Legionnaires' disease outbreak in Flint, Michigan. Proceedings of the National Academy of Sciences of the United States of America, v. 115, ed. 8, p. E1730-E1739, 2018. 